\title{
INVESTIGATIONS OF LARGE SCALE SINKHOLE COLLAPSES, LAIBIN, GUANGXI, CHINA
}

\author{
Yongli Gao \\ Department of Geological Sciences, Center for Water Research, University of Texas at San Antonio, TX 78249, USA, \\ yongli.gao@utsa.edu
}

Weiquan Luo, Xiaozhen Jiang, Mingtang Lei, Jianling Dai

Institute of Karst Geology, CAGS, Guilin, China, mingtanglei@hotmail.com

\begin{abstract}
A series of sinkholes collapsed at Jili village and Shanbei village, Laibin Guangxi, China in June 2010. A large underground stream exists in the north-south transect of the study area and passes the collapse site. Preliminary investigations revealed that extremely heavy rainfall between May 31 and June 12010 may have triggered this collapse event. The precipitation, as high as $469.8 \mathrm{~mm}$ within one day, was a record high in the study area. A long period of drought in 2009 followed by extremely heavy rainfall along with cave roof collapse may have caused the collapse event on June 3 2010. The "water hammer" effect and collapsetriggered earthquakes caused severe ground failure and fractures in residential houses and Jili Dam. Several collapse events were caused by extreme weather conditions in Guangxi over the past few years. Further studies of the relationship between extreme weather events and sinkhole collapses will help minimize the damage or impact to human infrastructure by avoiding areas susceptible to collapse or by designing infrastructure to better withstand subsidence.
\end{abstract}

\section{Introduction}

On June 3 2010, four extremely large sinkholes collapsed at Jili village and Shanbei village, Laibin Guangxi, China. These sinkholes expanded and merged to form a $200 \mathrm{~m}$ long collapse zone. Many ground failures and fractures occurred in the area. An area of $0.4 \mathrm{~km}^{2}$ was impacted by the collapse event. Because the collapses occurred in areas with a high density of population, initial investigation results reveal severe damage to residential houses. A total of 130 families, more than 600 people, a dam and a highway were impacted by the collapse event. This paper discusses the geologic background, possible mechanism of sinkhole collapses, and future studies of sinkhole hazard assessment in the study area.

\section{Geologic Settings}

Jili village is located in central Guangxi province, a highly active karst area containing many karst features such as sinkholes, springs, karst windows, caves, and conduit systems (Figure 1).

The study area is a typical fengcong and fenglin karst area with isolated and dissolved hills and valleys. The unconsolidated sediments above bedrock are Quaternary alluvium and colluvium. Quaternary deposits consist of silty clay, clay containing gravels, and clay. Karst bedrock units belong to the middle Carboniferous Huanglong Formation $\left(\mathrm{C}_{2 \mathrm{~h}}\right)$ and Nandan Formation $\left(\mathrm{C}_{2 \mathrm{n}}\right)$. Rock types include thick light-gray limestone, gray fossiliferous limestone, dolomite limestone, siliceous and fossiliferous limestone, limestone containing gravels,

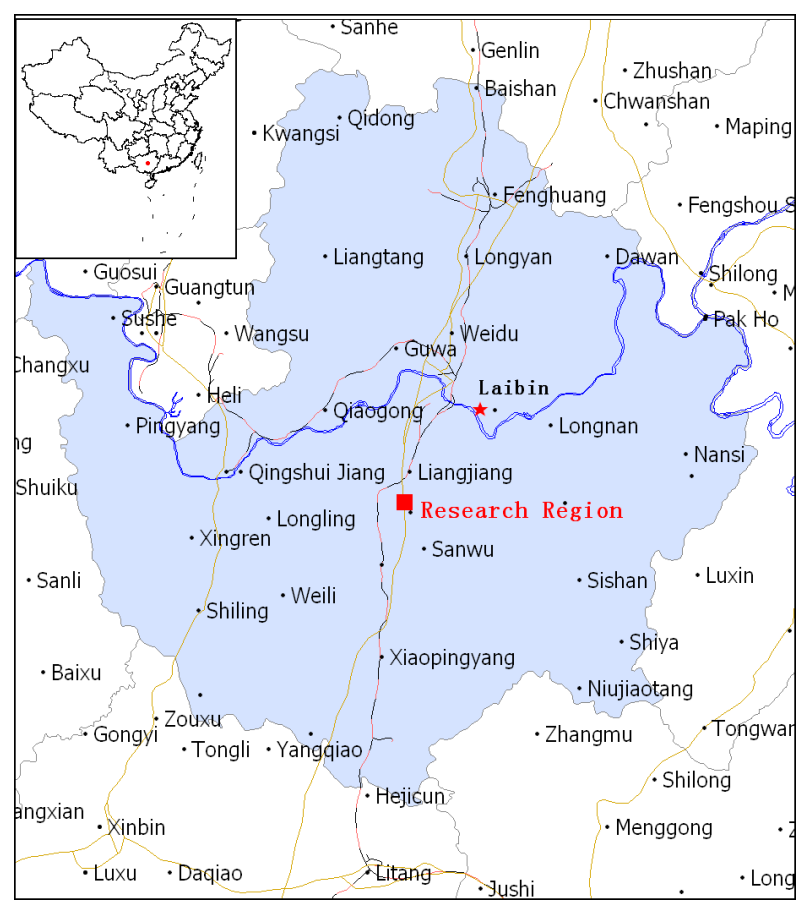

Figure 1. Geographic location of Laibin. 
and dolostone. Non-karstic bedrock units belong to the lower Cretaceous Yongfu Formation $\left(\mathrm{K}_{2 \mathrm{y}}\right)$. Rock types include reddish arkosic sandstone and mudstone.

Surface water and Quaternary groundwater are scarce in the study area. Groundwater resources include karst water within bedrock matrix, fracture, and conduits and a limited amount of Quaternary water in porous sediments. Fairly large springs exist in the area, which are recharged through sinkholes, active karst fractures and conduits. Three large springs with discharge rates of $100-1336.5$ 1/s are located near Liangxian. Approximately 100 - 400 $\mathrm{m}^{3} /$ day of water discharges out of drilled holes. Hongshui River, located $16 \mathrm{~km}$ north of the study area, marks the regional level for base flow, which receives water from most base flow groundwater in the study area.

Preliminary investigations of sinkholes, subsidence areas, and large springs reveal that a large cave stream exists in the study area at nearly a $\mathrm{N}$ - S orientation. The three large springs may serve as discharge outlets of the cave stream. The cave stream passes through the sinkhole plain and discharges to Chenglong Creek, a tributary of Hongshui River.

\section{Sinkhole Distribution}

Preliminary investigations revealed that extremely heavy rainfall between May 31 and June 12010 may have triggered this collapse event (Figure 2). The precipitation, as high as $469.8 \mathrm{~mm}$ within one day, was a record high amount in the study area (Figure 3 ).

Two earthquakes at Richter scale of $1.9-2.0$ were recorded on June 1 by the Guangxi Bureau of Earthquake Investigation. The first sinkhole collapsed at 9:00 am on June 3, 2010. Four extremely large sinkhole pits formed within 3 hours. These sinkholes expanded and merged to form a $200 \mathrm{~m}$ long collapse zone (Figure 4). Walls of these sinkholes are not stable and these sinkholes kept growing after the initial collapse (Figure 5).

Earthquakes which occurred on June 1 were probably caused by cave roof collapses. The "water hammer" effect caused by cave roof collapse can release a pressure surge to the karst conduit system and sediments overlying the karst conduit, causing severe soil damage and subsequent collapses (Lei et al., 2010;

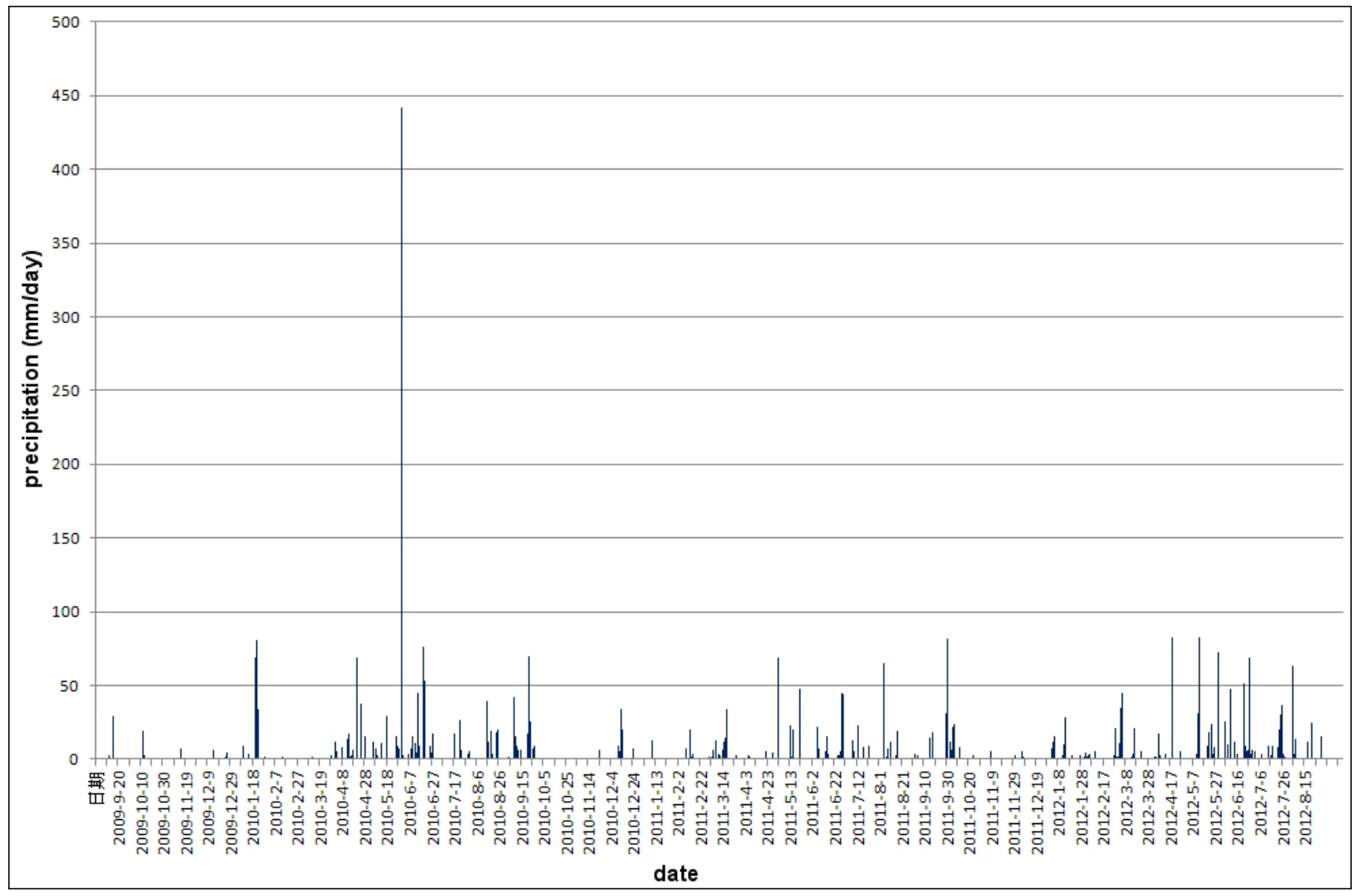

Figure 2. Daily precipitation between September 2009 and August 2012 in the study area. 


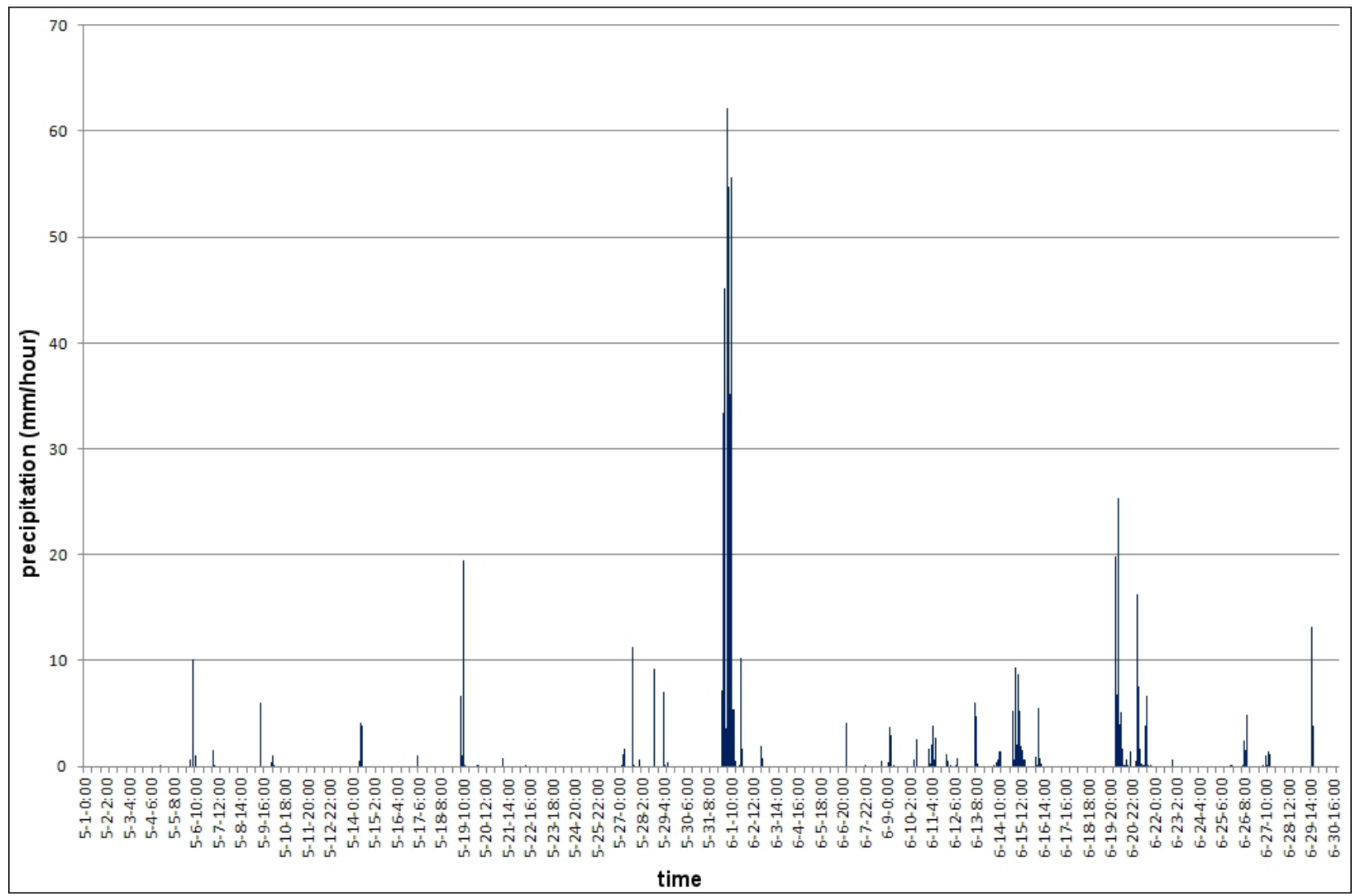

Figure 3. Hourly precipitation between May 1 and June 42012 in the study area.

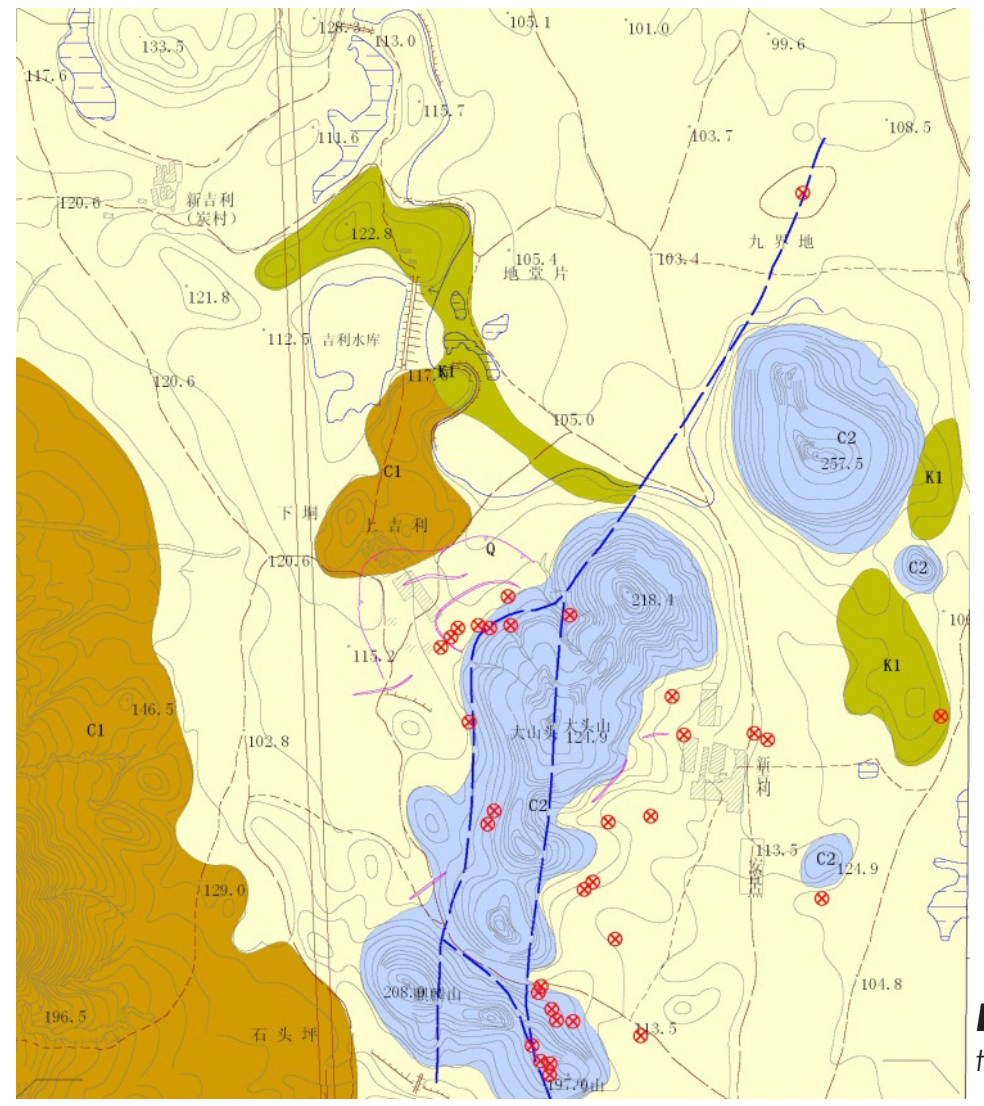

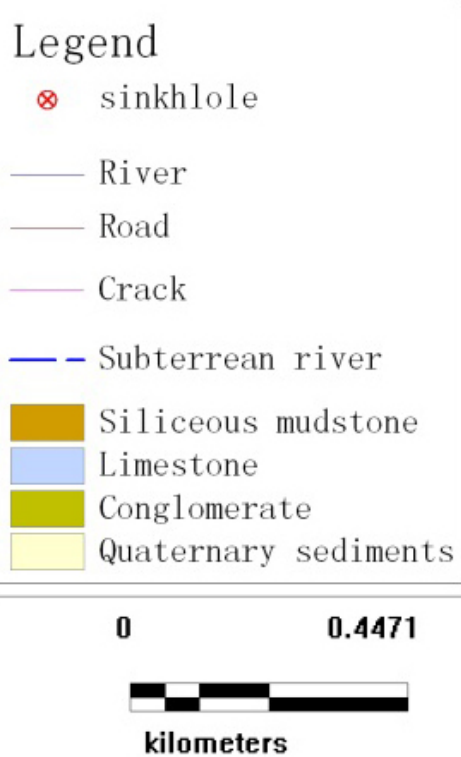

Scale: 1:9,005

Figure 4. Sinkhole distribution in the study area. 


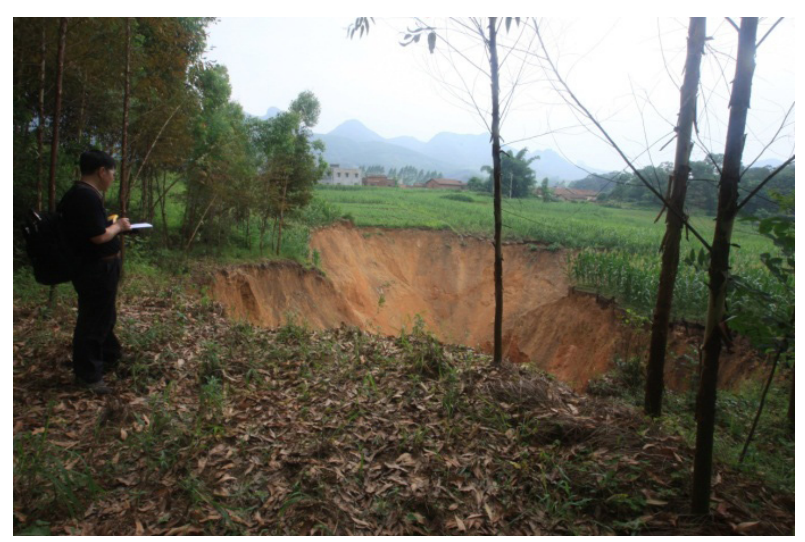

Figure 5. Sinkhole no. 3 with unstable walls.

Lei et al., 2013). Earthquakes and the "water hammer" effect may also have caused fractures in many houses and the Jili Dam (Figures 6 and 7).

\section{Conclusions}

Rapid water level rise after the storm event caused a series of sinkhole collapses in the study area. Several collapse events were associated with extreme weather conditions in Guangxi over the past few years (Lei et al., 2013). Further studies of the relationship between extreme weather events and sinkhole collapses will help minimize the damage or impact to human infrastructure by avoiding areas susceptible to collapse or by designing infrastructure to better withstand subsidence.

An on-site investigation revealed that initial collapses occurred during heavy rainfall. The precipitation, as high as $469.8 \mathrm{~mm}$ within one day, was a record high amount in the study area. A long period of drought in 2009 followed by extremely heavy rainfall along with cave roof collapse may have caused the collapse event

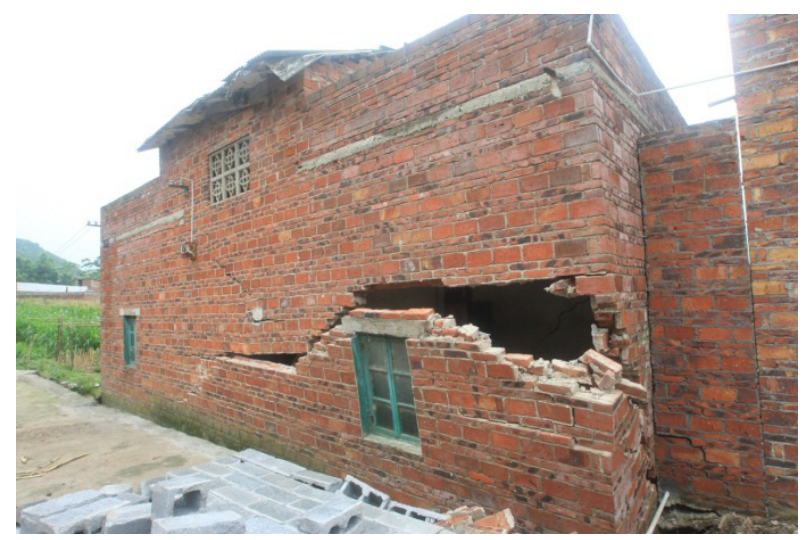

Figure 6. Ground failure and damage to a residential house.

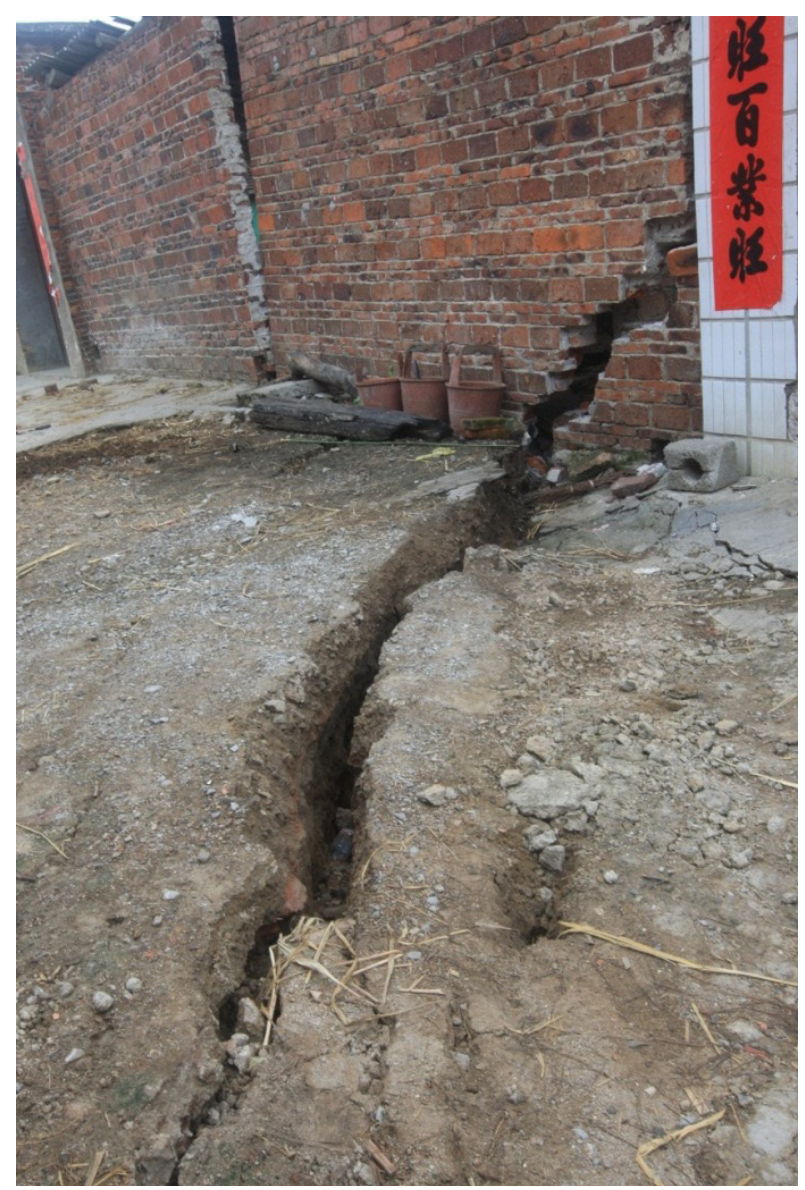

Figure 7. Fracturing through ground and houses.

on June 3 2010. Cave roof collapse may trigger a "water hammer" effect in the karst conduits. The "water hammer" effect can cause severe soil damage and trigger subsequent collapses (Lei et al., 2010; Lei et al., 2013). Soil disturbance may change hydraulic gradient, which can cause water level fluctuations and eventually result in sinkhole collapses.

Recommended techniques for assessing sinkhole hazards include: potentiometric mapping, locating areas of disturbed soil and soil voids using ground penetrating radar (GPR), monitoring karst groundwater pressure changes, sinkhole inventories, and tracer test of surface water and groundwater interaction. These approaches are being conducted in other areas to prevent or forecast sinkhole collapses and to minimize the damage caused by sinkhole collapses (Jiang et al., 2008; Jiang et al., 2013; Lei et al., 2008; Lei et al., 2010).

Karst water levels are recovering to normal conditions after the collapse event. It may take several years to 
stabilize the soil to normal conditions. A $10 \mathrm{~m} \times 10 \mathrm{~m}$ soil collapse area was recently discovered in the south portion of the study area. A donut shaped subsidence area formed around the new collapse site. The diameter of the subsidence area is $100 \mathrm{~m}$ with ground failures and fractures formed inside the subsidence area. This area is located directly above the subterranean stream. Large scale sinkhole collapses may occur again during monsoon seasons. Residents in Jili village and Shanbei village may need to be relocated to a safer place. Jili Dam and Guibei highway need to be evaluated for further damage.

\section{Acknowledgements}

Field assistance and cooperation of local residents in Jili village and Shanbei village are highly appreciated. We thank Harry Moore and Brad Stephenson for their helpful reviews.

\section{References}

Jiang X, Lei M, Gao Y, Meng Y, Sang X. 2008. Monitoring soil void formation along highway subgrade using Time Domain Reflectometry (TDR), a pilot study at Guilin-Yangshuo highway, Guangxi, China. In: Yuhr L, Alexander E, Beck B, editors. Proceedings of the Eleventh Multidisciplinary Conference on Sinkholes and the Engineering and Environmental Impacts of Karsts. ASCE Geotechnical Special Publication no. 183. p. 213-222.

Jiang X, Lei M, Gao Y, Guan Z. 2013. Characterization of Karst Collapse Hazard Based on Groundwater Fluctuations in Qingyun village, Guigang, Guangxi, China (this volume).

Lei M, Gao Y, Li Y, Meng Y, Yu L, Gan F. 2008. Detection and treatment of sinkholes and subsurface voids along Guilin - Yangshuo highway, Guangxi, China. In: Yuhr L, Alexander E, Beck B, editors. Proceedings of the Eleventh Multidisciplinary Conference on Sinkholes and the Engineering and Environmental Impacts of Karsts. ASCE Geotechnical Special Publication, no. 183. p. 632-639.

Lei M, Jiang X, Li Y, Meng Y, Dai J, Gao Y. 2010. Predicting sinkhole collapse by long-term monitoring of karst water pressure in Zhemu, China. Geologically Active: Proceedings of the 11th IAEG Congress, Auckland, New Zealand. p. 355-362.

Lei M, Gao Y, Jiang X, Guan Z. 2013. Emergency Investigation of Extremely Large Sinkholes, Maohe, Guangxi, China (this volume). 
